\title{
Study on the Construction of the Teaching Staff for the Improvement of Rural Human Capital in Tianjin
}

\author{
Xinyu Liu \\ School of Economics and Management \\ Tianjin Agricultural College \\ Tianjin, China
}

\author{
Zixuan Wang \\ School of Economics and Management \\ Tianjin Agricultural College \\ Tianjin, China
}

\author{
Zheng Wang* \\ School of Economics and Management \\ Tianjin Agricultural University \\ Tianjin, China \\ wangzheng7007@163.com.
}

\begin{abstract}
Rural human capital is of great significance to the economic development of rural areas in Tianjin, is the premise and basis for accelerating rural economic development, and is the support and guarantee for realizing the rural revitalization strategy. To upgrade rural human capital, the most rapid and crucial is to strengthen the standardized management and scientific education of rural human capital. Therefore, the construction of rural human capital teachers has become an important link to improve rural human capital. This paper aims to analyze and summarize the problems existing in the construction of the faculty of rural human capital in Tianjin by reading a large number of relevant literature, policies and field visit investigations. At the same time, it draws on the successful experience at home and abroad and proposes feasible suggestions.
\end{abstract}

Keywords-Rural human capital; Rural Revitalization; Peasant education; Teacher team building

\section{THE DEFINITION OF RURAL HUMAN CAPITAL AND RURAL HUMAN CAPITAL TEACHERS}

\section{A. Definition of Rural Human Capital}

Human capital, also known as "immaterial capital", is opposite to "material capital". Capital embodied in workers, such as workers' knowledge and skills, cultural and technological level and health status. Some Chinese scholars put forward the definition of rural human capital on the basis of the concept of human capital. Generally speaking, rural human capital is the capital condensed on rural labor force through a series of means such as education and training.

\section{B. Definition of Rural Human Capital Teachers}

Teachers of rural human capital refer to a group of teachers specializing in the promotion of rural human capital. It is a group specializing in the transmission of human scientific and cultural knowledge and skills, ideological and moral education, and the cultivation of educators into laborers and specialized talents needed by the society[1].

\section{PRESENT SITUATION OF RURAL HUMAN CAPITAL TEACHERS IN TIANJIN}

Since 2003, in order to improve the quality of farmers, Tianjin has organized a series of training projects and plans, which has played a tremendous role in promoting and guaranteeing the construction of human capital teachers in rural areas.

\section{A. Scale and Achievement Status of Teachers}

In 2017, Tianjin identified 46 rural peasant training institutions, including Wuqing and Baodi districts as the first pilot farmer training units, adopting flexible and diverse training modes such as night schools, on-site demonstration teaching and providing near-by training services; selecting excellent teachers to conduct theoretical training, leading students to visit various regions, combining with practical activities, so as to enable them to Members change their thinking, broaden their horizons and enrich their experience. In 2017, 5000 new vocational peasants were trained, of which 1376[2] were trained in difficult villages, which provided a source of help to promote the construction of rural human capital teachers in Tianjin. However, with the increasing number of peasant students, the number of teachers and training institutions is not meeting the market demand.

\section{B. Current Situation of Teachers' Management System}

In order to strengthen the management of training institutions and teachers, Tianjin issued the Circular of the Municipal Agricultural Commission on the Issue of Interim Measures for the Management of Tianjin Farmers' Education and Training Institutions in 2017. The notice requires all training institutions and teachers to strictly comply with the specific requirements of peasant education and training, abide by the application system for opening classes, the class 
management system and the file management system, improve the education and training management information system, and control all links before, during and after training, so as to ensure the quality of training [3].

\section{The Present Situation of Ideological Concepts}

Tianjin Rural Human Capital Education Teachers Team is an advanced part of the whole system. Although they are constantly trained and educated in moral concepts and political literacy and can complete various tasks on time, there are still some teachers who do not really understand and approve their own career, lack strict requirements for their work, and are only mechanical indicators for the completion of various tasks. Teachers 'enthusiasm, initiative and creativity are far from being brought into play.

\section{Current Situation of Comprehensive Professional Level and Quality of Teachers}

At present, Tianjin's teaching staff engaged in rural human capital education has two forms of part-time and full-time employment. Some of the teachers come from major agricultural colleges and universities. These teachers have received systematic education and training. They not only have rich experience in teaching management, but also have a better understanding of the theoretical knowledge of agriculture, countryside and farmers. Their professional level and quality are excellent. However, most of them are part-time teachers from social organizations or institutions, and most of them have not mastered the subject. To learn reasonable teaching methods, we do not have a complete knowledge system of subjects and lack of relevant practical experience. There are inevitably shortcomings in the training of farmers, and we need to further improve the relevant professional level.

\section{E. Current situation of legal system construction of Teachers}

In order to speed up the construction of human capital teachers in rural areas, the state and Tianjin Municipal Government have issued new policies to support them. For example, on May 26, 2010, Tianjin Regulations on Peasant Education and Training were voted on at the 17th meeting of the Standing Committee of the 15th People's Congress of Tianjin. The Regulations marked the gradual legalization of peasant education and training in Tianjin, pointed out the way forward for peasant education and training, and also put forward the requirements and guarantee for teachers and training institutions. In 2014, Tianjin promulgated the "Opinions of Tianjin Municipal People's Government on Implementing the Welfare Plan for Training Millions of Skilled Talents", emphasizing those teachers should play a leading role.

\section{Problems Existing In TIANJin RuRAL Human CAPITAL TEACHERS}

\section{A. The scale of teaching staff needs to be further expanded}

In addition to the flow of objective personnel caused by new and old replacements and job mobilization, full-time teachers have basically no major changes; the size of part-time teachers is relatively stable[4], in recent years, with the increasing number of rural human capital in need of education, the size of teachers and the number of training institutions began to appear inadequate, the results of training and education are not as ideal as before, so the number of Teachers and institutions urgently need to be further expanded.

\section{B. The management system of teachers should be further improved}

At present, Tianjin has made specific requirements for the management of the teachers' team in terms of the system to be followed and the obligations to be fulfilled. However, there are no specific and detailed regulations on the teacher appointment system, transfer system and promotion mechanism. Sometimes, the particularity and demand of human capital education activities in rural areas are not taken into account. There exists a phenomenon of more random allocation of teachers, which may result in demand. To some extent, it wastes educational resources because teachers of disciplines can't come in, but teachers of disciplines are surplus.

\section{Strengthen the education of teachers' thoughts}

Due to various reasons, some teachers lack enthusiasm and patience for the education cause of improving rural human capital, lack enthusiasm and initiative for work, lack of motivation for research and exploration of the methods and methods of education and teaching, and can't effectively apply existing knowledge and experience to work, and carry out various tasks mechanically with the mentality of "doing a day monk strikes a day clock". Indicators, lack of continuous learning, improve their own quality of positive attitude.

\section{Professional level and quality of teachers need to be further improved}

At present, part-time teachers engaged in rural human capital education are members of social organizations and institutions. They are temporary lecturers of some courses in rural human capital education. They have little or no training in agricultural production technology. The lack of specific teaching methods and theoretical knowledge often makes it difficult for these teachers to teach students in accordance with their aptitude according to their physical and mental development characteristics and the actual situation in rural areas. Therefore, it is necessary to carry out education and training on the professional level and basic quality of these teachers in order to improve the comprehensive strength of the entire teaching staff.

\section{E. The Legal Construction of Teachers' Team Needs Further Improvement}

With the continuous advancement and rapid development of rural human capital education, many countries and regions have recognized the importance of establishing laws and regulations on rural human capital education for rural education, and have promulgated and revised relevant legal systems. Although Tianjin took the lead in promulgating a series of provisions in the whole country, clarifying the requirements and guarantees for human capital teachers in rural areas, it has not formulated specific implementation rules, and the implementation effect is not satisfactory. 


\section{SUgGESTIONS ON THE CONSTRUCTION OF RURAL HUMAN CAPITAL TEACHERS IN TIANJIN}

\section{A. Improving the Scale of Teachers}

In order to match the number of teachers with the number of students, Tianjin should expand the recruitment of rural human capital education teachers. First of all, many college graduates, especially those from agricultural schools, are facing difficulties in finding jobs and become idle talents. This provides an opportunity to recruit teachers of human capital education in rural areas. We should use this opportunity to introduce graduates with high educational background and professional knowledge and inject fresh blood into the teaching staff of human capital education in rural areas. Secondly, teachers should be recruited from outside schools or units to further enrich the teaching staff, broaden the existing knowledge and skills of the team, increase the vitality of the team, and make use of the mutual exchange and learning between teachers from different sources to promote the progress of the team and achieve complementary advantages.

\section{$B$. Improving the management system and standardize the management mode of Teachers}

To formulate a more perfect recruitment plan, recruitment requirements, qualifications and promotion mechanism for rural human capital education teachers, clarify the recruitment process, and make it open and transparent. To conduct a strict preliminary qualification and review for teachers who want to enter the rural human capital education team, teachers who do not meet the recruitment requirements will not be recruited. Selecting high-quality and high-level teachers who are really keen on human capital education in rural areas.

\section{Strengthening Ideological Education}

We should pay attention to the cultivation of teachers' ideological concepts, strengthen the understanding of education and love teaching. To cultivate the spirit of love and dedication, so that it can withstand the confusion of the outside world, adhere to the post of teaching and educating people, and avoid coping with psychology. At the same time, we should set up the concept of lifelong education and lifelong learning. We should constantly expand our knowledge scope, update our knowledge reserves, adjust our knowledge structure and broaden our knowledge horizon according to our own knowledge structure and ability, combined with the characteristics and needs of human capital learning in rural areas, so as to improve our moral and cultural qualities to meet the needs of more and more diverse cultures and the demand of human capital education in rural areas.

\section{Strengthening the training of teachers to improve professional quality and overall quality}

In order to ensure and continuously improve the quality of teacher training in rural human capital education, Tianjin should build a reasonable curriculum system for teacher training. The curriculum includes not only the training courses of educational and teaching knowledge and skills, but also the training courses of improving teachers' academic degree, political and moral concepts and ideological literacy. The training of professional teaching ability, basic theoretical knowledge and moral quality of some non-professional teachers should be strengthened in all aspects, so as to improve the quality of the whole teaching staff.

\section{E. Further Improve and Implement the Relevant Legal System}

Legislation is fundamental to realize the rapid development of rural human capital education and to establish and improve the educational system of forming rural human capital in an all-round way. Although Tianjin has issued a series of laws and regulations to guarantee the rural human capital teachers, they are not detailed enough. On the basis of existing regulations, the welfare benefits and social status of teachers should be further explained and protected in detail. At the same time, we should really govern education according to law, implement a series of rules and regulations, and make the training of teachers orderly. Developing it will help education develop in the direction of lifelong education [4].

\section{CONCLUSION}

In today's society, developed science and technology, advanced theoretical knowledge, and rich teaching resources are the foundations for improving the education of rural human capital. However, the core leading factor to ensure the quality and level of education and teaching is always the construction of the teaching team. To effectively improve the construction of Tianjin's rural human capital teachers, it is necessary to focus on the reform of the team's scale, management, ideological, moral and legal systems. This is a long-term work, and it is a difficult historical task. It cannot be achieved by the efforts of the education department, education experts and scholars, the state and the government. It requires the support and active participation of the whole society.

\section{REFERENCES}

[1] Li Yan. Research on the Construction of Adult Education Teachers in Chongqing Rural Areas under the Background of Coordinating Urban and Rural Areas. Southwest University, April-30, 2011

[2] Summary of Cultivation of New Professional Farmers, 2017

[3] Circular of the Municipal Agricultural Commission on the Issuance of Interim Measures for the Administration of Farmer Education and Training Institutions in Tianjin

[4] Yang Peng. Reference Significance of American Adult Education Teacher Training Experience. Continuing Education Research, 2017-11-15 